Luciana Dias Bernardo ${ }^{\mathrm{a}}$

(iD) https://orcid.org/0000-0003-1757-0504

Eduardo Borba Neves ${ }^{\mathrm{a}, \mathrm{b}}$

(ID) https://orcid.org/0000-0003-4507-6562

a Universidade Federal do Rio de Janeiro (UFRJ), Instituto de Estudos em Saúde Coletiva. Rio de Janeiro, RJ, Brasil.

b Universidade Tecnológica Federal do Paraná (UTFPR), Programa de Pós-graduação em Engenharia Biomédica. Curitiba, PR, Brasil.

Contato:

Eduardo Borba Neves

E-mail:

eduardoneves@utfpr.edu.br

Os autores declaram que o trabalho não foi subvencionado e que não há conflitos de interesses.

Os autores informam que o trabalho não é baseado em dissertação ou tese e não foi apresentado em evento científico.

\section{Fatores de risco para perda auditiva em militares da Marinha: uma revisão}

\author{
Risk factors for hearing loss in naval military personnel:
}

a review

\section{Resumo}

Introdução: militares estão expostos ao ruído em grande parte de suas atividades profissionais. Objetivo: identificar os fatores de risco e descrever os danos à audição relacionados à exposição ao ruído em atividades militares navais. Métodos: revisão de literatura nas bases bibliográficas Scopus, Web of Science e SciELO. Buscou-se artigos originais publicados de 2007 a 2017. A qualidade metodológica dos estudos foi classificada segundo critérios da Cochrane Collaboration. Resultados: de 47 estudos encontrados, sete atenderam aos critérios de inclusão. Os artigos selecionados evidenciaram que as atividades militares apresentam riscos para a saúde auditiva do pessoal militar naval. Os estudos confirmaram que os casos de perda auditiva aumentam com o tempo de serviço em atividade militar e pós-atividades operativas, tanto de combate quanto a bordo de navios. A prevalência de perda auditiva aumenta junto à idade e ao tempo de exposição dos indivíduos e se apresenta de acordo com o tipo de ruído. É mais frequente entre homens brancos e atinge predominantemente as altas frequências da audição, sendo de tipo sensório-neural. Conclusão: a vulnerabilidade desse grupo reforça a necessidade de inserção de programa de conservação auditiva nas organizações militares a fim de monitorar e desenvolver ações preventivas voltadas a essa categoria profissional.

Palavras-chave: audição; perda auditiva provocada por ruído; saúde do trabalhador; militares.

\begin{abstract}
Introduction: military personnel are exposed to noise in most of their professional activities. Objective: to identify risk factors and describe hearing damage related to noise exposure in naval military activities. Methods: literature review in Scopus, Web of Science and SciELO bibliographic bases. We searched original articles published from 2007 to 2017. The studies were classified according to the methodological quality Cochrane Collaboration criteria. Results: out of 47 studies, seven met the inclusion criteria. The selected articles showed that the naval military personnel's hearing health can be affected by military activities. The studies confirmed that hearing loss cases increase according to the length of time spent in military and post-operative activities, both in combat and on board of ships. The hearing loss prevalence increases with age and time of exposure, and is featured according to the type of noise. It is more frequent among white men and reaches predominantly the hearing high frequencies, being of sensorial-neural type. Conclusion: the vulnerability of this group reinforces the need for implementing hearing conservation programs within military organizations in order to monitor and develop preventive actions aimed at this professional category.
\end{abstract}

Keywords: hearing; hearing loss, noise-induced; occupational health; military personnel. 


\section{Introdução}

A perda de audição ocupacional é uma das doenças mais comuns relacionadas ao trabalho. Dados internacionais mostram que cerca de 22 milhões de trabalhadores nos Estados Unidos da América (EUA) estão expostos a níveis perigosos de ruído no trabalho a cada ano ${ }^{1,2}$. No Brasil, mesmo com a subnotificação desse agravo, sabe-se que a perda auditiva induzida por níveis de pressão sonora elevadas ainda é frequente ${ }^{3}$. Sendo assim, a perda auditiva e suas consequências são importantes problemas de saúde pública em nível mundial ${ }^{4,5}$.

O ruído é um agente físico, descrito como som indesejado que, em decorrência de uma constante exposição acima dos limites de tolerância - determinados conforme o tempo e sua intensidade -, pode trazer consequências em curto prazo, como: falta de concentração, esgotamento, irritação, desconforto, além do deslocamento temporário do limiar auditivo, que é decorrente de um estresse metabólico excessivo das células ciliadas sensoriais. Em longo prazo, com a persistente exposição, a capacidade de recuperação das células ciliadas é reduzida, levando, então, a uma mudança permanente do limiar ${ }^{6,7}$.

Na exposição do trabalhador ao ruído, fatores específicos do agente, do ambiente e da suscetibilidade individual são considerados condicionantes e agravantes do processo de saúde e doença. De acordo com o modelo de História Natural das Doenças (HND), nenhum agente será por si só suficiente para desencadear o processo patológico ${ }^{8}$.

Os membros do Serviço Militar, aos quais não se aplica a observância das Normas Regulamentadoras (NR) do extinto Ministério do Trabalho, são frequentemente expostos a altos níveis de ruído ocupacional, solventes e outras exposições que podem ser prejudiciais para o sistema auditivo ${ }^{4,9-11}$. A exposição desses trabalhadores é análoga ao trabalho civil, porém a atenção à sua saúde faz-se de forma diferenciada devido às suas relações trabalhistas regulamentadas pelo Estatuto dos Militares ${ }^{11}$.

No ambiente militar, a audição é fundamental para o rápido e preciso processamento das informações da fala e identificações de sinais auditivos, imprescindíveis à sobrevivência em situações táticas e não táticas ${ }^{4,9,12}$. A escuta pode ser influenciada por vários fatores, tais como: idade, hereditariedade, traumatismo craniano, tabagismo, doenças sistêmicas, exposição a substâncias químicas e/ou ruído ocupacional, e atividades de lazer ${ }^{13}$.

Diante disso, os riscos de danos pela exposição ao ruído podem estar presentes em diversas situações, por exemplo: no treinamento de armas, na artilharia, em uma aeronave, na fabricação, na construção, na manutenção, no transporte, ou ainda em exposições inesperadas, como em uma explosão ${ }^{2,14-16}$. Além disso, em grande parte das Forças Navais, nos períodos de treinamento ou de atividades marítimas, os sujeitos são expostos aos intensos barulhos de motores dos navios, carros de combate e práticas de tiro, além de fatores agravantes que podem potencializar seus riscos, como a exposição às substancias químicas ${ }^{3,17}$.

Estudos realizados nas Forças da Noruega, EUA e Reino Unido, produzidos a bordo de navios e em operações táticas de fuzileiros, apontam que as operações navais produzem níveis de ruído potencialmente prejudiciais à saúde humana ${ }^{18-20}$. Outro estudo, realizado no departamento de defesa dos EUA, apontou um aumento nas reivindicações por invalidez entre os veteranos da Marinha, decorrente de perda auditiva no ano de $2013^{2}$. Esse fato corroborou os achados de outro estudo, realizado no mesmo país, que apresentou a cifra de U\$ 108 milhões pagos em prêmios por invalidez a 15.800 militares da Marinha, em 2004, em função de perdas auditivas ${ }^{18}$.

O Exército e o Corpo de Fuzileiros Navais dos EUA foram os grupos de militares que obtiveram o maior número de diagnósticos de perda de audição, por membros do serviço ativo, encontrados nos dados do Defense Occupational and Environmental Health Readiness System Hearing Conservation (DOEHRS-HC) ${ }^{2}$.

No Brasil, estudos sobre a ocorrência de perda auditiva na Marinha são infrequentes, e não estão claras quais ocupações nessa atividade profissional estão associadas a esses desfechos indesejáveis, tampouco quais as intensidades, seus agentes e tipos de perdas auditivas dela decorrentes. Diante desse cenário, torna-se pertinente questionar: quais são os fatores de risco e que tipos de danos auditivos podem advir das atividades militares navais?

A relevância em traçar o perfil auditivo de trabalhadores da Força Naval consolida-se devido à necessidade de conhecer os desfechos indesejáveis e seus fatores de risco para que se possa pensar em intervenções que mitiguem os danos à saúde auditiva desses militares. Nesse sentido, esta revisão teve como objetivo identificar os fatores de risco e descrever os danos à audição relacionados à exposição ao ruído em atividades militares navais.

\section{Métodos}

Foi realizada uma revisão nas bases de dados bibliográficos Web of Science (WoS), Scopus e Scientific Electronic Library Online (SciELO). Com base na indagação proposta, foi utilizada uma estratégia de busca com a combinação de descritores indexados no Medical Subject Headings (MeSH) e Descritores em Ciências da Saúde (DeCS). As consultas ocorreram de 10 de julho a 10 de dezembro de 2017. Os descritores utilizados, segundo a base bibliográfica consultada, estão apresentados no Quadro 1. 
Quadro 1 Descritores da busca por fatores de risco para perda auditiva em militares da Marinha, 2017

\begin{tabular}{|c|c|}
\hline Base de dados & Descritores \\
\hline Scopus & (“hearing” OR “audition” OR “auditory threshold”) AND (“navy personnel” OR “marines” OR “personnel, navy" OR “sailors”) \\
\hline WoS & (“hearing” OR “audition” OR “auditory threshold”) AND (“navy personnel” OR “marines” OR “personnel, navy” OR “sailors”) \\
\hline SCIELO & (“audição” OR “limiar auditivo”) AND (“marinheiros” OR “pessoal da marinha” OR “fuzileiros navais”) \\
\hline
\end{tabular}

Os critérios de inclusão foram: artigos originais e completos na língua portuguesa, inglesa ou espanhola; publicados no período de janeiro de 2007 a novembro de 2017; incluindo militares da Marinha. Foram excluídos artigos incompletos, artigos de revisão e aqueles que não se referiam aos militares da Marinha. A Figura 1 apresenta o fluxograma da seleção dos artigos científicos localizados.

Para a primeira fase de identificação dos estudos, foram catalogados todos os artigos encontrados nas bases de dados selecionadas, conforme descritores apresentados no Quadro 1. Para a fase de seleção, foram feitas as análises de todos os títulos identificados e seus resumos, mantendo apenas aqueles que se adequavam aos critérios de inclusão e eliminando os artigos duplicados. Para a fase de elegibilidade, os artigos em que o título ou o corpo do resumo fomentaram dúvidas a respeito do tema em questão foram levantados na íntegra, julgados quanto à pertinência e posteriormente incluídos ou descartados.

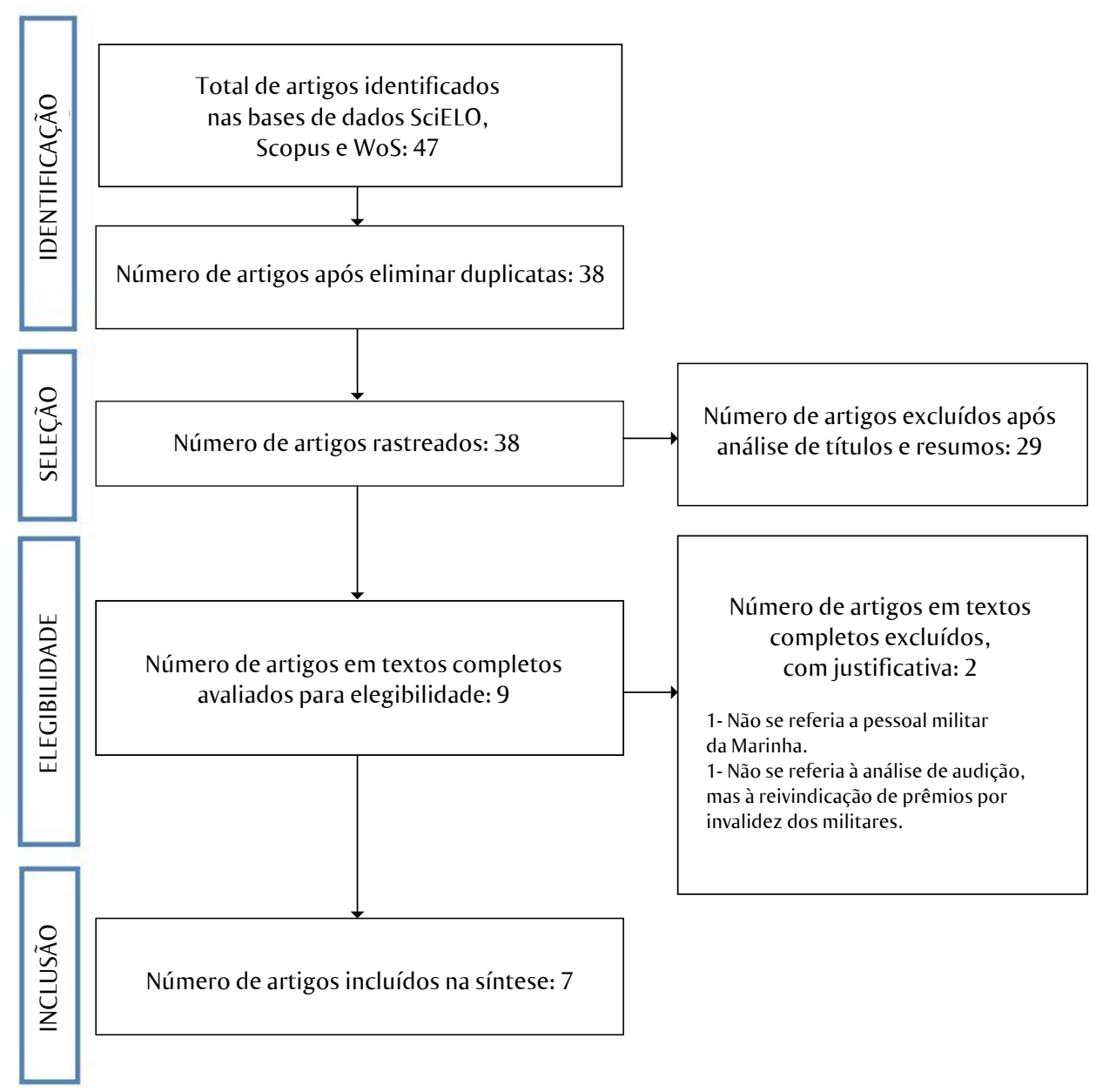

Figura 1 Fluxograma da seleção dos artigos publicados a respeito de fatores de risco para perda auditiva em militares da Marinha, 2007-2017 
A qualidade metodológica dos estudos foi classificada por meio da tabela adaptada da avaliação de qualidade da Cochrane Collaboration relativa ao risco de viés ${ }^{21}$. Foram analisados oito itens: especificação de critérios de inclusão; presença de justificativa para o tamanho da amostra; presença de grupo controle; ausência de viés de seleção; pesquisa realizada para avaliar pessoal da Marinha; qualidade da avaliação realizada para pesquisar as vias auditivas; exposição a agente nocivo e conclusão compatível com os resultados. Cada uma dessas questões foi respondida com "sim" ou "não". As avaliações dos artigos utilizaram pontuação variando de 0 a 8 pontos, em que cada requisito valia 1 ponto. Foram considerados artigos de ótima qualidade os que variaram nas notas de 7 a 8 , qualidade moderada os que apresentaram pontuação entre 4 a 6 e de baixa qualidade aqueles que obtiveram pontuação inferior a 4 . A maior parte (5 de 7, correspondendo a 71,4\%) dos artigos obteve nota 7 , o que indica baixo risco de viés.

\section{Resultados}

Conforme apresentado na Figura 1, as buscas nas bases de dados identificaram 47 estudos publicados acerca do tema pesquisado. Foram 35 artigos encontrados na Scopus, 12 na WoS e zero na SciELO. Inicialmente, foram excluídos nove artigos em duplicata. Dos 38 restantes, 29 foram excluídos nas análises de títulos e resumos por não estarem relacionados ao assunto pesquisado ou não tratarem de militares da Marinha. Os nove estudos restantes tiveram seus textos analisados por completo. Da leitura integral desses nove artigos, observou-se a necessidade da exclusão de dois deles, pois um não tratava de militares da Marinha, e o outro não analisava a audição destes militares. Sendo assim, sete artigos atenderam aos critérios de inclusão da pesquisa.

Os sete artigos $12,18-20,22-24$ selecionados estão apresentados na Tabela 1, por categorização das amostras, e na Tabela 2, por objetivos, análises e desfechos encontrados, além do resultado da avaliação de qualidade dos estudos.

Para fins didáticos, as perdas auditivas foram reproduzidas com a nomenclatura fiel aos estudos, contudo, todas apresentam relação com a atividade ocupacional. Utilizou-se os termos noise-induced hearing loss (NIHL), presente no estudo de Pearson ${ }^{19}$ e indexado no DeCS com seu sinônimo, perda auditiva induzida por ruído (PAIR). Outro estudo ${ }^{23}$ referiu-se a sensorineural hearing loss (SNHL) (perda auditiva sensório neural - PASN).

Segundo Protocolo do Ministério da Saúde ${ }^{3}$, a PAIR apresenta as seguintes características: é sempre neurossensorial (sensório neural), geralmente bilateral, irreversível e progressiva com o tempo de exposição. A perda auditiva induzida por níveis elevados de pressão sonora não ocasiona deficiência maior que $40 \mathrm{~dB}$ (nível de audição - NA) nas frequências baixas, e maior que $75 \mathrm{~dB}$ (NA) nas altas. Seu início e predomínio ocorrem nas frequências de 3, 4 ou $6 \mathrm{kHz}$, posteriormente progredindo para níveis de $8 \mathrm{kHz}$, ou regredindo para 2, 1, 0,5 e $0,25 \mathrm{kHz}^{3}$.

Dos sete artigos analisados, um apresentou dados da população da Marinha Real Britânica ${ }^{19}$, outro da Marinha Real da Noruega ${ }^{20}$, e os demais mostraram dados da Marinha Americana ${ }^{12,18,22-24}$. Todos foram publicados na língua inglesa.

A maior parte dos estudos abordou o efeito do agente físico ruído, seja ele contínuo, intermitente ou de impacto, na audição desses militares ${ }^{12,19,20,22,23}$. Apenas um estudo não deixou claro a que tipo de exposição os militares estavam sujeitos, abordando de forma genérica a questão do risco auditivo existente após entrada para o serviço militar ${ }^{24}$.

A população de militares foi diversificada quanto às suas especialidades, apresentando: grupos de Fuzileiros Navais em atividade operativa, em treinamento ou lesionados após batalha; aviadores e servidores a bordo de navios. Houve dois estudos que também abordaram militares de outras Forças Armadas, como Soldados do Exército ${ }^{24}$ e pilotos militares do Exército e da Força Aérea ${ }^{23}$.

As amostras variaram de grupos de 38 indivíduos a 467.064 sujeitos. Apenas três pesquisas não apresentaram seus dados utilizando a estratificação por sexo ${ }^{12,19,23}$, duas utilizaram etnia dentre suas variáveis ${ }^{18,24}$, e duas não utilizaram idade na caracterização $^{12,19}$.

Com a finalidade de identificar as alterações na saúde auditiva desses militares, apenas dois estudos realizaram a coleta com dados primários, utilizando o exame de audiometria tonal ${ }^{12,20}$ - em um deles foi aplicado um questionário sobre exposição ao ruído ${ }^{20}$. Uma avaliação objetiva da audição e o exame de emissões otoacústicas também foram aplicados ${ }^{12}$. Os demais estudos utilizaram dados secundários por meio do acesso aos resultados de exames das bases de dados com registros dos militares, pertinentes a cada local de estudo.

Dentre os sete trabalhos analisados, dois eram estudos de coorte retrospectiva ${ }^{22,23}$; dois eram do tipo caso-controle ${ }^{18,24}$; um exploratório descritivo ${ }^{19}$; um transversal ${ }^{20}$; e um estudo longitudinal ${ }^{12}$. Os estudos tiveram como objetivo conhecer os efeitos da exposição ocupacional na audição dos combatentes.

Todos os estudos evidenciaram que as atividades militares representam um ambiente de trabalho incomum, que apresenta riscos para a saúde e segurança auditiva do pessoal militar. Foi observado também o aumento na prevalência de perdas auditivas após entrada para o serviço militar e pós-atividades operativas, tanto de combate quanto a bordo de navios. 
Tabela 1 Caracterização das amostras dos estudos incluídos na revisão sobre fatores de risco para perda auditiva em militares da Marinha, 2007-2017

\begin{tabular}{|c|c|c|c|c|c|c|c|c|}
\hline Autor/ano & Tipo de estudo & População & $N^{o}$ & Sexo & Idade & Etnia & Tempo de serviço & Ocupação \\
\hline $\begin{array}{l}\text { Trost e Shaw } \\
(2007)^{18}\end{array}$ & Caso-controle & $\begin{array}{l}\text { Marinheiros alistados } \\
\text { durante o período de } \\
1979 \text { a } 2004\end{array}$ & 267.658 & $\begin{array}{l}\text { MASCULINO: } \\
87,96 \% \\
\text { FEMININO: } 12,04 \%\end{array}$ & $\begin{array}{l}17 \text { a } 64 \text { anos } \\
\text { (média: } 27,51 \text { ) }\end{array}$ & $\begin{array}{l}\text { Caucasianos: } \\
61,40 \% \\
\text { Afro- } \\
\text { americanos: } \\
\text { 18,34\% } \\
\text { Hispânicos: } \\
\text { 10,68\% } \\
\text { Asiáticos: } \\
\text { 6,23\% } \\
\text { Outros: 3,38\% }\end{array}$ & $\begin{array}{l}6,79 \text { anos em } \\
\text { média }\end{array}$ & $\begin{array}{l}\text { Anos em média } \\
\text { Ala aérea: } 4,48 \\
\text { Anfíbio: } 2,78 \\
\text { Transportador: } \\
3,04 \\
\text { Combatente de } \\
\text { superfície: } 3,43 \\
\text { Submarino: } 4,74 \\
\text { Navio de apoio: } \\
3,10 \\
\text { Costa: } 3,37\end{array}$ \\
\hline $\begin{array}{l}\text { St Onge, } \\
\text { Mcllwain, } \\
\text { Hill, Walilko } \\
\text { e Bardolf } \\
(2011)^{12}\end{array}$ & Longitudinal & $\begin{array}{l}\text { Fuzileiros navais } \\
\text { inscritos no Breacher } \\
\text { Training Course }\end{array}$ & $\begin{array}{l}38 \text { no exame } \\
\text { audiométrico; } \\
26 \text { no exame } \\
\text { de emissões } \\
\text { otoacústicas, } \\
\text { porque alguns } \\
\text { participantes } \\
\text { não } \\
\text { completaram } \\
\text { as medidas pós- } \\
\text { treinamento. }\end{array}$ & Não estratificou & $\begin{array}{l}\text { Não } \\
\text { estratificou }\end{array}$ & $\begin{array}{l}\text { Não } \\
\text { estratificou }\end{array}$ & $\begin{array}{l}\text { Antes e depois } \\
\text { do curso/ } \\
\text { treinamento }\end{array}$ & Combatentes \\
\hline $\begin{array}{l}\text { Pearson } \\
(2011)^{19}\end{array}$ & $\begin{array}{l}\text { Exploratório } \\
\text { descritivo }\end{array}$ & Fuzileiros navais & 181 & Não estratificou & $\begin{array}{l}\text { Não } \\
\text { estratificou }\end{array}$ & $\begin{array}{l}\text { Não } \\
\text { estratificou }\end{array}$ & $\begin{array}{l}\text { Antes e depois } \\
\text { do curso/ } \\
\text { treinamento }\end{array}$ & Combatentes \\
\hline $\begin{array}{l}\text { Orsello, } \\
\text { Moore } \\
\text { e Reese } \\
(2013)^{23}\end{array}$ & $\begin{array}{l}\text { Coorte } \\
\text { retrospectiva }\end{array}$ & $\begin{array}{l}\text { Militares em serviço } \\
\text { ativo dentro do Exército, } \\
\text { Marinha, Força Aérea e } \\
\text { fuzileiros navais entre os } \\
\text { anos de } 1997 \text { e } 2011\end{array}$ & $\begin{array}{l}467.064 \\
\text { pessoas/ano }\end{array}$ & Não estratificou & $\begin{array}{l}\text { Pareou por } \\
\text { idade, sem } \\
\text { descrever o } \\
\text { total de sujeitos } \\
\text { por faixa etária } \\
(20-29,30-39 \\
\text { e } 40+)\end{array}$ & $\begin{array}{l}\text { Não } \\
\text { estratificou }\end{array}$ & Não estratificou & $\begin{array}{l}\text { Pilotos de } \\
\text { aeronave de asas } \\
\text { fixas e rotativas }\end{array}$ \\
\hline $\begin{array}{l}\text { Gubata, } \\
\text { Packnett, } \\
\text { Feng, Cowan } \\
\text { e Niebuhr } \\
(2013)^{24}\end{array}$ & Caso-controle & $\begin{array}{l}\text { Casos: militares com } \\
\text { avaliação específica } \\
\text { de perda auditiva para } \\
\text { o serviço. Controles: } \\
\text { não avaliados para } \\
\text { deficiência antes do final } \\
\text { do período de estudo }\end{array}$ & $\begin{array}{l}877 \text { casos } \\
+1.860 \\
\text { controles. } \\
\text { Frequência } \\
\text { corresponde } \\
\text { ao ano de } \\
\text { entrada e ramo } \\
\text { de serviço aos } \\
\text { casos com uma } \\
\text { proporção } \\
\text { de } 5: 1\end{array}$ & $\begin{array}{l}\text { Caso: } \\
\text { masculino: } 364 \\
\text { feminino: } 8 \\
\text { Controle } \\
\text { masculino: } 1.528 \\
\text { feminino: } 330\end{array}$ & $\begin{array}{l}\text { (casos/ } \\
\text { controles): } \\
<20 \text { anos } \\
(42,2 \% / 50,3 \%) \\
20-24 \\
(33,3 \% / 32,3 \%) \\
25-29 \\
(14,8 \% / 9,6 \%) \\
>30 \text { anos } \\
(9,7 \% / 7,7 \%)\end{array}$ & $\begin{array}{l}\text { (casos/ } \\
\text { controles): } \\
\text { Brancos } \\
(87,4 \% / 77,3 \%) \\
\text { Negros } \\
(5,6 \% / 16,3 \%) \\
\text { Outros } \\
(6,7 \% / 5,6 \%) \\
\text { Perda } \\
\text { amostral } \\
(0.3 \% / 0.8 \%)\end{array}$ & $\begin{array}{l}1^{\circ} \text { ano e } 2^{\circ} \text { ano } \\
\text { de alistamento }\end{array}$ & $\begin{array}{l}\text { Soldados do } \\
\text { Exército dos EUA } \\
\text { e do Corpo de } \\
\text { Fuzileiros Navais; }\end{array}$ \\
\hline $\begin{array}{l}\text { Irgens- } \\
\text { Hansen, } \\
\text { Sude, } \\
\text { Bråtveit, } \\
\text { Baste, } \\
\text { Oftedal, } \\
\text { Koefoed, } \\
\text { et al. }(2015)^{20}\end{array}$ & Transversal & $\begin{array}{l}\text { Pessoal da Marinha que } \\
\text { trabalha a bordo dos } \\
\text { navios da Marinha Real } \\
\text { Norueguesa (oficiais, } \\
\text { recrutas e civis) }\end{array}$ & 605 & $\begin{array}{l}\text { Masculino: } 569 \\
\text { Feminino: } 36\end{array}$ & $\begin{array}{l}19 \text { a } 62 \text { anos } \\
\text { (Média: } 30 \\
\text { anos) }\end{array}$ & $\begin{array}{l}\text { Não } \\
\text { estratificou }\end{array}$ & $\begin{array}{l}\text { Ponderado por } \\
4 \text { subcategorias } \\
\text { dentro de: } \\
\text { Serviço na } \\
\text { Marinha: } \\
\text { > } 11 \text { anos } \\
\text { Embarcado: } \\
\text { > } 9 \text { anos } \\
\text { Navegando: } \\
>3 \text { anos }\end{array}$ & $\begin{array}{l}\text { Eletricista: } 106 \\
\text { Convés: } 88 \\
\text { Escritório dos } \\
\text { navios: } 36 \\
\text { Cozinha: } 25 \\
\text { Sala de operação: } \\
118 \\
\text { Navegador: } 119 \\
\text { Sala de máquinas: } \\
108\end{array}$ \\
\hline $\begin{array}{l}\text { Joseph, } \\
\text { Horton, } \\
\text { Clouser, } \\
\text { MacGregor, } \\
\text { Louie e } \\
\text { Galarneau } \\
(2016)^{22}\end{array}$ & $\begin{array}{l}\text { Coorte } \\
\text { retrospectiva }\end{array}$ & $\begin{array}{l}\text { Servidores da Marinha e } \\
\text { do Corpo de Fuzileiros } \\
\text { Navais com lesão sofrida } \\
\text { em batalha }\end{array}$ & 16.525 & $\begin{array}{l}\text { Masculino: } 16.025 \\
(97 \%) ; \text { Feminino: } \\
500(3 \%)\end{array}$ & $\begin{array}{l}\text { Média: } 24 \\
\pm 5,7 \\
\text { Faixa etária: } \\
<21(23,8 \%) \\
21-28(59,5 \%) \\
29-36(11,4 \%) \\
37-44(4,2 \%) \\
>44(1,1 \%)\end{array}$ & $\begin{array}{l}\text { Não } \\
\text { estratificou }\end{array}$ & Não estratificou & Não informado \\
\hline
\end{tabular}


Tabela 2 Análise dos estudos incluídos na revisão sobre fatores de risco para perda auditiva em militares da Marinha, 2007-2017

\begin{tabular}{|c|c|c|c|c|c|}
\hline $\begin{array}{l}\text { Referêncial } \\
\text { ano } \\
\text { (Qualidade } \\
\text { cochrane) }\end{array}$ & Objetivo & Exposição & Forma de análise & Coleta de dados & Resultados \\
\hline $\begin{array}{l}\text { Trost e Shaw } \\
(2007)^{18} \\
(7 / 8)\end{array}$ & $\begin{array}{l}\text { Determinar como } \\
\text { a perda auditiva } \\
\text { está relacionada ao } \\
\text { tempo de serviço } \\
\text { gasto a bordo dos } \\
\text { navios }\end{array}$ & Ruído & $\begin{array}{l}\text { Análises binomiais logísticas } \\
\text { e logarítmicas observando } \\
\text { mudança para três frequências } \\
\text { ( } 2 \mathrm{kHz}, 3 \mathrm{kHz} \text { e } 4 \mathrm{kHz} \text { ) entre } \\
\text { os audiogramas do primeiro } \\
\text { e do último ano + cálculo do } \\
\text { número de meses servindo } \\
\text { em diferentes tipos de } \\
\text { navio (guerras de superfície, } \\
\text { submarinos e de apoio) e } \\
\text { quatro categorias de trabalho } \\
\text { (motores, máquinas, aeronaves } \\
\text { ou outros). Controle: homem } \\
\text { caucasiano de qualquer idade, } \\
\text { sem tempo gasto a bordo de } \\
\text { um navio ou em um local de } \\
\text { destino na costa. } \\
\text { Razão de risco (RR): } 1,0\end{array}$ & $\begin{array}{l}\text { Registros de audiogramas do Defense } \\
\text { Occupational and Environmental Health } \\
\text { Readiness System (DOEHRS-HC) + dados } \\
\text { sobre o tempo gasto em diferentes } \\
\text { locais de destino do Registro Enlisted } \\
\text { Master Record (EMR) }\end{array}$ & $\begin{array}{l}\text { Perda auditiva mais prevalente } \\
\text { com a idade e em caucasianos. } \\
\text { Tempo de serviço: metade } \\
\text { do tempo de uma carreira de } \\
30 \text { anos gasto em um navio de } \\
\text { guerra ( } 0,48 \text { de probabilidade de } \\
\text { desencadeamento de perda); } \\
\text { 2/3 do tempo em um navio de } \\
\text { guerra de superfície }(0,53) \text {; carreira } \\
\text { inteira em um local de destino na } \\
\text { costa }(0,35) \text {. O tempo gasto em um } \\
\text { determinado tipo de navio teve um } \\
\text { impacto maior na perda auditiva do } \\
\text { que o tempo gasto em postos de } \\
\text { destino na costa }\end{array}$ \\
\hline $\begin{array}{l}\text { St Onge, } \\
\text { Mcllwain, } \\
\text { Hill, Walilko } \\
\text { e Bardolf } \\
(2011)^{12} \\
(7 / 8)\end{array}$ & $\begin{array}{l}\text { Determinar se os } \\
\text { Fuzileiros Navais } \\
\text { estavam em risco } \\
\text { de lesão durante } \\
\text { as práticas de } \\
\text { treinamento } \\
\text { padrão enfocando } \\
\text { unicamente os } \\
\text { efeitos auditivos e } \\
\text { vestibulares }\end{array}$ & $\begin{array}{l}\text { Exposição } \\
\text { a explosão } \\
\text { e choque } \\
\text { físico }\end{array}$ & $\begin{array}{l}\text { Compararam dados } \\
\text { observacionais coletados } \\
\text { pré-treinamento, durante } \\
\text { treinamento e pós-treinamento } \\
\text { entre setembro e junho de } \\
2007 \text {. Avaliou os limiares de } \\
500 \mathrm{~Hz}, 1 \mathrm{kHz}, 2 \mathrm{kHz}, 3 \mathrm{kHz}, \\
4 \mathrm{kHz}, 6 \mathrm{kHz} \text { e } 8 \mathrm{kHz} \text { antes do } \\
\text { início do treinamento e após a } \\
\text { conclusão do treinamento na } \\
\text { audiometria. A diferença nas } \\
\text { emissões otoacústicas (EOA) } \\
\text { dos produtos de distorção } \\
\text { foi comparada a } 1.828 \mathrm{~Hz}, \\
2.016 \mathrm{~Hz}, 3.047 \text { Hz e } 4.124 \\
\text { Hz antes e após a conclusão } \\
\text { do treinamento. Avaliou a } \\
\text { influência do treinamento de } \\
\text { breacher sobre o equilíbrio } \\
\text { estático e dinâmico com a } \\
\text { avaliação de estabilidade e teste } \\
\text { dinâmico de acuidade visual }\end{array}$ & $\begin{array}{l}\text { Audiometria tonal; emissões } \\
\text { otoacústicas; avaliação de estabilidade; } \\
\text { teste dinâmico de acuidade visual }\end{array}$ & $\begin{array}{l}\text { Perda auditiva foi estatística e } \\
\text { clinicamente significativa mesmo } \\
\text { com proteção auditiva aprovada, } \\
\text { enquanto os achados vestibulares } \\
\text { não foram abrangentes. Aumento } \\
\text { estatisticamente significante nas } \\
\text { frequências de: } 1,2 \text { e } 3 \text { kHz para } \\
\text { audiometria e } 3.047 \text { Hz para EOA } \\
\text { (p<.01). Avaliação de estabilidade } \\
\text { com achados clinicamente pouco } \\
\text { significativos. No teste dinâmico } \\
\text { de acuidade visual grupo de } \\
\text { movimentos de cabeças foi } \\
\text { significativo, mostrando uma } \\
\text { degradação significativamente } \\
\text { menor do desempenho de pré para } \\
\text { pós-avaliação do que os controles } \\
\text { para a direção de movimento } \\
\text { esquerda e direita }\end{array}$ \\
\hline $\begin{array}{l}\text { Pearson } \\
(2011)^{19} \\
(5 / 8)\end{array}$ & $\begin{array}{l}\text { Estimar a } \\
\text { prevalência de PAIR } \\
\text { após operação } \\
\text { Herrick } 9\end{array}$ & Ruído & $\begin{array}{l}\text { Análise comparativa, usando } \\
\text { qui-quadrado, dos resultados } \\
\text { audiométricos do pessoal } \\
\text { envolvido nas operações } \\
\text { militares Herrick } 9 \text { e RAFWittering }\end{array}$ & $\begin{array}{l}\text { Audiometria tonal do DAS (defence } \\
\text { audiology service) realizadas durante } \\
\text { outubro e novembro de } 2009 \text {. } \\
\text { Audiometrias utilizadas no estudo } \\
\text { com os militares que realizaram o RAF } \\
\text { Wittering em } 1999\end{array}$ & $\begin{array}{l}69 \% \text { apresentaram evidência de } \\
\text { PAIR após a Herrick } 9 \text { para entalhe } \\
\text { de } 10 \mathrm{~dB}(\mathrm{p}<0,001) .47 \% \text { para } \\
\text { entalhe de } 15 \mathrm{~dB}(\mathrm{p}<0,001) \text { e } \\
\text { prevalência de } 33 \% \text { para entalhe } \\
\text { de } 20 \mathrm{~dB}(\mathrm{p}<0,001)\end{array}$ \\
\hline $\begin{array}{l}\text { Orsello, } \\
\text { Moore } \\
\text { e Reese } \\
(2013)^{23} \\
(6 / 8)\end{array}$ & $\begin{array}{l}\text { Determinar se há } \\
\text { diferença entre a } \\
\text { taxa média anual de } \\
\text { incidência de Perda } \\
\text { Auditiva Sensório- } \\
\text { Neural (PASN) entre } \\
\text { aviadores de asas } \\
\text { fixas e rotativas no } \\
\text { Exército dos EUA, } \\
\text { Marinha, Força } \\
\text { Aérea e Fuzileiros } \\
\text { Navais }\end{array}$ & Ruído & $\begin{array}{l}\text { Análise estatística de variância } \\
\text { de duas vias e multivariadas } \\
\text { (ANOVA); interação entre os } \\
\text { efeitos: ramo militar (Exército, } \\
\text { Marinha, Força Aérea e } \\
\text { Fuzileiros Navais); tipo de } \\
\text { aeronave (fixo X rotativo) nas } \\
\text { taxas anuais médias de PASN } \\
\text { durante o período estudado. } \\
\text { Anova multivariada foi } \\
\text { realizada em todas as idades } \\
\text { do aviador: } 20-29,30 \text {-39 e } \\
\text { acima de } 40 \text { anos }\end{array}$ & $\begin{array}{l}\text { Audiogramas do banco de dados da } \\
\text { Defense Medical Epidemiology Database } \\
\text { (DMED) - Centro de Vigilância da Saúde } \\
\text { das Forças Armadas }\end{array}$ & $\begin{array}{l}\text { A taxa de incidência média anual } \\
\text { de PASN foi estatisticamente } \\
\text { significante para o tipo de } \\
\text { aeronave (asas fixas) e ramo } \\
\text { militar (Exército e Força Aérea). } \\
\text { A idade teve um efeito } \\
\text { significativo, de modo que as } \\
\text { taxas anuais médias de PASN } \\
\text { foram maiores para as idades } \\
\text { de } 30 \text {-39 e aqueles com idade } \\
\text { acima de } 40 \text {. A interação entre } \\
\text { os três fatores (ramo de serviço, } \\
\text { tipo de aeronave e idade) não } \\
\text { teve impacto estatisticamente } \\
\text { significante }\end{array}$ \\
\hline
\end{tabular}


Tabela 2 Continuação...

\begin{tabular}{|c|c|c|c|c|c|}
\hline $\begin{array}{l}\text { Referência/ } \\
\text { ano } \\
\text { (Qualidade } \\
\text { cochrane) }\end{array}$ & Objetivo & Exposição & Forma de análise & Coleta de dados & Resultados \\
\hline $\begin{array}{l}\text { Gubata, } \\
\text { Packnett, } \\
\text { Feng, Cowan } \\
\text { e Niebuhr } \\
(2013)^{24} \\
(7 / 8)\end{array}$ & $\begin{array}{l}\text { Identificar os } \\
\text { fatores de risco } \\
\text { para perda auditiva } \\
\text { relacionados à } \\
\text { incorporação ao } \\
\text { serviço militar }\end{array}$ & $\begin{array}{l}\text { Não } \\
\text { definido }\end{array}$ & $\begin{array}{l}\text { Análise de frequência } \\
\text { descritiva para: fins médicos, } \\
\text { características demográficas } \\
\text { e tempo de serviço. Análise } \\
\text { categórica (Qui-quadrado): } \\
\text { comparou a distribuição da } \\
\text { incidência de perda auditiva no } \\
\text { atendimento ambulatorial por } \\
\text { tempo de serviço. Regressão } \\
\text { logística condicional: } \\
\text { examinou a associação entre } \\
\text { adesão e fatores de risco } \\
\text { relacionados ao serviço e } \\
\text { avaliação da perda auditiva }\end{array}$ & $\begin{array}{l}\text { Banco de dados do Exército dos } \\
\text { EUA - Physical Disability Agency, } \\
\text { para Soldados - e da Marinha dos } \\
\text { EUA - Council of Review Board para os } \\
\text { Fuzileiros Navais (dados administrativos } \\
\text { e médicos, incluindo os audiogramas) }\end{array}$ & $\begin{array}{l}\text { Análise de regressão logística } \\
\text { condicional: OR (Odds ratio - } \\
\text { razão de chances) para } \\
\text { deficiência ( } 8,2 \text { para sexo } \\
\text { masculino; } 0,65 \text { para a raça } \\
\text { negra; } 1,38 \text { para idade entre } \\
25 \text { e } 29 \text { anos; } 1,78 \text { durante sua } \\
\text { carreira militar). Mais que } 70 \% \\
\text { dos casos e controles que se } \\
\text { alistaram com audiogramas } \\
\text { normais apresentaram perda } \\
\text { de audição após incorporação. } \\
\text { Dos audiogramas normais } \\
\text { (pré-alistamento): } 60,6 \% \text { dos } \\
\text { casos, } 84,4 \% \text { dos controles } \\
\text { tiveram perda auditiva após o } \\
2^{\circ} \text { ano de serviço. Concluiu que } \\
\text { a incorporação para o serviço } \\
\text { militar de combate está associada } \\
\text { ao aumento de perda de audição }\end{array}$ \\
\hline $\begin{array}{l}\text { Irgens- } \\
\text { Hansen, } \\
\text { Sunde, } \\
\text { Bråtveit, } \\
\text { Baste, } \\
\text { Oftedal, } \\
\text { Koefoed et } \\
\text { al. }(2015)^{20} \\
(7 / 8)\end{array}$ & $\begin{array}{l}\text { Avaliar a prevalência } \\
\text { da perda auditiva } \\
\text { e examinar sua } \\
\text { associação com o } \\
\text { trabalho a bordo } \\
\text { dos navios da } \\
\text { Marinha Real } \\
\text { Norueguesa }\end{array}$ & Ruído & $\begin{array}{l}\text { Calculou o limiar de } \\
\text { audição por idade e gênero } \\
\text { e comparação deste com } \\
\text { os limiares de audição } \\
\text { medidos dos participantes } \\
\text { (categorizados por função } \\
\text { no navio). Associação entre } \\
\text { as variáveis de exposição ao } \\
\text { trabalho (anos de trabalho } \\
\text { na Marinha, anos nos navios } \\
\text { e anos de navegação na } \\
\text { Marinha). O limiar auditivo } \\
\text { para cada frequência foi } \\
\text { analisado por regressão } \\
\text { linear fornecendo } \beta \text { e IC 95\% } \\
\text { (intervalo de confiança) }\end{array}$ & $\begin{array}{l}\text { Questionário sobre exposição ao ruído } \\
\text { e audiometria tonal }\end{array}$ & $\begin{array}{l}31,4 \% \text { apresentou perda auditiva } \\
\text { em } 3,000,4,000 \text { ou } 6,000 \mathrm{~Hz} \text {. A } \\
\text { prevalência foi significativamente } \\
\text { maior entre navegadores }(37,0 \%) \\
\text { e pessoal da sala das máquinas } \\
(38,0 \%) \text { em relação aos eletricistas } \\
(23,6 \%) \text {. Prevalência de perda } \\
\text { auditiva de } 50,3 \% \text { nos militares } \\
\text { acima de } 33 \text { anos e } 23,0 \% \text { entre os } \\
\text { menores de } 24 \text { anos. O pessoal } \\
\text { da Marinha que navegou mais } \\
\text { de três anos apresentou uma } \\
\text { prevalência de perda auditiva de } \\
46,4 \% \text {, enquanto a prevalência } \\
\text { foi de } 26,4 \% \text { entre o pessoal da } \\
\text { Marinha que navegou por menos } \\
\text { de um ano. Entre as variáveis de } \\
\text { exposição ao trabalho, os anos } \\
\text { de navegação foram o maior } \\
\text { preditor de perda auditiva }\end{array}$ \\
\hline $\begin{array}{l}\text { Joseph, } \\
\text { Horton, } \\
\text { Clouser, } \\
\text { MacGregor, } \\
\text { Louie e } \\
\text { Galarneau } \\
(2016)^{22} \\
(7 / 8)\end{array}$ & $\begin{array}{l}\text { Examinar os efeitos } \\
\text { da lesão causada } \\
\text { por explosões } \\
\text { na sensibilidade } \\
\text { auditiva } \\
\text { determinando a } \\
\text { taxa de perda de } \\
\text { audição }\end{array}$ & Explosão & $\begin{array}{l}\text { Análise, usando qui-quadrado, } \\
\text { do limiar de audição e dados } \\
\text { de resultados de saúde } \\
\text { registrados antes e depois } \\
\text { da lesão }\end{array}$ & $\begin{array}{l}\text { Banco de dados audiométricos - } \\
\text { audiometria tonal via aérea ( } 51.516 \\
\text { audiogramas de } 16.525 \text { membros de } \\
\text { serviço) ( } 89 \% \text { com audiogramas pré- } \\
\text { lesão; } 70 \% \text { pós-lesão) }\end{array}$ & $\begin{array}{l}39 \% \text { com perda auditiva em } \\
\text { pelo menos um audiograma. } \\
19 \% \text { bilateral. } 13 \% \text { unilateral } \\
\text { esquerda. } 7 \% \text { unilateral direita. } \\
22 \% \text { em alta frequência ( } p \\
<0,001 \text { ), sendo } 9 \% \text { em baixas } \\
\text { frequências e significantemente } \\
\text { maior à esquerda ( } p<0,001) \text {. } \\
13,8 \% \text { com sintoma de zumbido } \\
\text { auto-relatado }\end{array}$ \\
\hline
\end{tabular}

\section{Discussão}

A perda auditiva é a doença ocupacional de maior prevalência no Departamento de Defesa dos EUA e é também a deficiência relacionada ao trabalho mais recorrente no mundo ${ }^{25}$. Nessa revisão sistemática, foram analisados sete estudos que avaliaram as consequências da exposição ao ruído, dos postos de trabalho e do tempo de serviço na saúde auditiva de militares da Marinha.
Alguns estudos ${ }^{18,24}$ sugerem que a perda auditiva é mais prevalente em homens em comparação às mulheres; observaram ainda um fator de risco aumentado por raças, concluindo que os caucasianos são os mais acometidos. A maior parte dos estudos analisados abordou os danos auditivos com diferenciação por sexo e reforçou a ideia de que esse tipo de dano é predominante no sexo masculino, considerando a população estudada. A prevalência em questão pode 
ser justificada devido à superioridade numérica do sexo masculino nos estudos expostos, como se verifica nos estudos de Trost e Shaw ${ }^{18}$ e de Joseph et al..$^{22}$, que representam uma população de estudo de $87,96 \%$ e $97 \%$ de homens, respectivamente. Ainda que a entrada das mulheres nas fileiras das Forças Armadas se apresente em linha crescente, os cargos ainda são majoritariamente ocupados pelo sexo masculino ${ }^{26}$.

A literatura científica ${ }^{18,20,23,24}$ apresenta indícios de que o aumento da perda auditiva está intimamente relacionado ao aumento da idade. Diante disso, o fator idade foi levado em consideração na maioria dos estudos, por este ser um fator de risco que causa impacto negativo na audição e que é possível distrator dos resultados, caso seus efeitos não sejam controlados. A perda auditiva relacionada à idade afeta em torno de $60 \%$ das pessoas com mais de $65 \operatorname{anos}^{7,27}$. Devido à heterogeneidade dos estudos, pode-se observar que, em conjunto, eles cobriram uma população com idade mínima de 19 anos e máxima de 64 anos. O estudo de Irgens-Hansen et al. ${ }^{20}$ reportou que a perda foi significativamente associada à idade, no qual a prevalência de perda auditiva foi de 50,3\% para o grupo acima de 33 anos e $23 \%$ entre os menores de 24 anos. Tais resultados estão em acordo com aqueles observados no estudo de Orsello, Moore e Reese ${ }^{23}$, em que as taxas anuais médias de perda auditiva foram maiores para as idades acima de 30 anos.

Alguns autores ${ }^{12,19}$ não utilizaram o fator idade em sua pesquisa. O estudo de Joseph et al. ${ }^{22}$ apresentou média etária de 24 anos com desvio-padrão de 5,7 anos, porém a idade não era um critério da pesquisa - que tratava da perda da audição em lesões pós-batalha, podendo ter ocorrido a qualquer tempo na carreira. No referido estudo, $78 \%$ apresentaram lesões diversas pós-explosão, indicando a existência de 39\% de perda auditiva em pelo menos um audiograma analisado.

O tempo de serviço foi abordado de forma heterogênea nos estudos, mas inferiu-se que a incidência de perda auditiva aumenta quanto maior é o tempo de serviço considerado ${ }^{12,18-20,22-24}$.

O tempo de exposição em determinadas funções da Marinha também foi fator de risco para os danos auditivos. O estudo de Irgens-Hansen et al. ${ }^{20}$ apontou que os militares que navegaram mais de 3 anos apresentaram prevalência de perda auditiva de $46,4 \%$, e o pessoal que navegou menos de 1 ano apresentou taxa de $26,4 \%$. De modo similar, o estudo de Trost e Shaw ${ }^{18}$ mostrou que se metade do tempo de serviço de uma carreira de 30 anos de Marinha for gasto em um navio de guerra, a probabilidade para desencadeamento de perda auditiva é de $48 \%$, enquanto para uma carreira inteira em terra essa taxa baixa para $35 \%$.
Uma análise de audiogramas de soldados do Exército e fuzileiros navais ${ }^{24}$ demonstrou que $54,2 \%$ dos militares admitidos com audiogramas alterados tiveram seu primeiro atendimento ambulatorial para perda auditiva no $1^{\circ}$ ano de serviço. Em contrapartida, $60,6 \%$ dos casos e $84,4 \%$ dos controles, com exames normais pré-alistamento, apresentaram seu primeiro incidente de perda auditiva após o $2^{\circ}$ ano de serviço. Gubata et al. ${ }^{24}$ concluíram que a adesão ao serviço militar está associada ao aumento de perda de audição e, diante de seus resultados, destacam a importância de admitir ao serviço militar sujeitos sem perdas prévias de audição. Estudos expõem que, após iniciadas as primeiras alterações auditivas, sua progressão cessará somente quando finda a exposição ao ruído ${ }^{3,28}$ e de que nada adiantará admitir trabalhadores com audição "normal" se não houver ações de proteção auditiva eficiente ${ }^{28}$. Além disso, não há informação de que indivíduos com presença de PAIR estariam mais sensíveis ao ruído ${ }^{3}$.

Todos os artigos usaram o audiograma como fonte principal para mensurar a audição dos militares. A maior parte utilizou dados secundários como forma de captação dos limiares de audição, o que possibilitou trabalhos com expressivo número de sujeitos ${ }^{18,22-24}$, enquanto apenas o estudo de Pearson ${ }^{19}$ teve um número reduzido de sujeitos - 181 fuzileiros navais -, justificado pelo fato de ser um estudo que estima a prevalência de PAIR após uma manobra operativa. Os demais trabalhos ${ }^{12,20}$ realizaram audiometria tonal (com dados primários), questionário sobre exposição ao ruído $^{20}$ e teste de emissões otoacústicas ${ }^{12}$.

Não há exatidão acerca das horas trabalhadas nem dos níveis de decibéis a que estão expostos os militares contemplados na maioria dos estudos, exceto nos artigos em que a exposição havia sido por explosão ${ }^{12,22}$. Apenas um artigo detalhou que sua população de estudo estaria com exposição ocupacional acima de uma média ponderada pelo Office of the Chief of Naval Operations Instruction - 5100.19D $(8 \text { horas a } 84 \mathrm{dBA})^{18}$. Esses níveis atingem a média ponderada para ação do Programa de Segurança e Saúde Ocupacional brasileiro. No Brasil, é estabelecido o nível de $85 \mathrm{dBA}$, no tempo de 8 horas, pela NR 15 da Secretaria de Trabalho do Ministério da Economia. Contudo, os militares brasileiros trabalham com base em regulamentos e normas próprias e, por vezes, não atendem a essas $\mathrm{NR}^{11,29,30}$.

Quanto aos resultados encontrados nos perfis audiométricos, os estudos ${ }^{12,20,22,24}$ indicam que as faixas de audição das altas frequências são as mais atingidas no ambiente militar. Os demais estudos não reportaram esta característica das lesões auditivas encontradas. O estudo de Irgens-Hansen et al. ${ }^{20}$ encontrou uma associação entre exposição ao ruído 
e limiares de audição mais elevados em 1.000 e 4.000 Hz para todas as variações de atividades.

Já no estudo de Joseph et al. ${ }^{22}$, dos 39\% de militares que apresentaram pelo menos um audiograma alterado, 22\% eram nas altas frequências - um número significativamente maior do que nas baixas frequências. Para o trabalho de St Onge et al. ${ }^{12}$, as frequências alteradas foram 1.000, 2.000 e 3.000 $\mathrm{Hz}$ para audiometria e de $3.047 \mathrm{~Hz}$ para o exame de emissões otoacústicas.

O estudo de Gubata et al. ${ }^{24}$ abordou que na análise dos audiogramas pré-alistamento que não excediam o limiar auditivo em mais de $20 \mathrm{~dB}$ aumentaram as chances de perda auditiva em todas as frequências analisadas (500 a $8 \mathrm{kHz}$ ). Em particular, os audiogramas com essas características, nas frequências de 3 e $4 \mathrm{kHz}$, tiveram, respectivamente, 7,24 e 9,67 mais chances (Odds Ratio) de se tornar uma perda auditiva significativa.

Os estudos previamente citados $^{12,20,22,24}$ corroboram a teoria de que o ouvido humano é mais sensível às altas e menos às baixas frequências, mostrando que, em longo prazo, não há grandes efeitos nas frequências graves, e sim uma deterioração precoce da audição nas frequências de 1 a $4 \mathrm{kHz}$. O impacto inicial de deterioração nos casos de perda auditiva induzida por níveis elevados de pressão sonora é visto na faixa de frequência de 4 a $6 \mathrm{kHz}^{6,7,31}$.

Ainda complementarmente aos dados audiométricos, observou-se uma maior prevalência de alterações na orelha esquerda. No estudo de Joseph et al. ${ }^{22}$ pode-se observar que do total de perdas auditivas, $19 \%$ foram bilaterais, $13 \%$ na orelha esquerda e $7 \%$ na direita. No mesmo sentido, no estudo de Pearson $^{19}$, entre os audiogramas que apresentaram entalhe de $10 \mathrm{~dB}, 22 \%$ eram simétricos, 55\% do lado esquerdo e $23 \%$ do lado direito. Nos exames com entalhe de $15 \mathrm{~dB}$, 10\% foi bilateral, 25\% para esquerda e $12 \%$ para o lado direito.

No período definido para essa revisão sistemática, poucos foram os artigos encontrados acerca da audição dos militares das marinhas internacionais e nenhum deles foi realizado no Brasil, evidenciando a existência de poucos estudos publicados sobre a saúde auditiva dessa população. Por outro lado, a exposição auditiva insalubre faz parte da rotina de atividades militares ${ }^{3,17}$, pois há situações em que o uso dos equipamentos de proteção gera um conflito entre uma maior proteção e uma menor audibilidade na comunicação com parceiros, na escuta do ambiente, sons de aviso e da situação a que está exposto. Cabe ressaltar que esses sons são imprescindíveis para manutenção da consciência em situações de conflito, podendo comprometer a consciência situacional e a eficácia no campo operacional ${ }^{32,33}$.
Sendo assim, é essencial o desenvolvimento de estudos sobre o acompanhamento do perfil audiológico destes sujeitos.

As limitações desta pesquisa foram: 1) baixo número de estudos relacionados a militares da Marinha; 2) diversidade na natureza de atribuições militares estudadas, dificultando comparações concretas para os postos de trabalho, pois certas funções e ocupações podem aumentar o risco de desenvolvimento de perda auditiva induzida por níveis elevados de pressão sonora; 3) heterogeneidade nos tipos de estudo, variáveis utilizadas e exposições diferenciadas; 4) incapacidade de alguns estudos de afirmar que a perda de audição é decorrente da exposição ao ruído, por não terem sido pesquisados os fatores de atividades e hábitos não laborais a que possam estar expostos os militares no dia a dia.

Entretanto, ainda com essas limitações, este trabalho consolida informações importantes que podem servir de base para refletir sobre o processo de trabalho e a saúde desta categoria de trabalhadores.

\section{Conclusão}

As informações acessadas confirmam a necessidade de se preocupar com a ocorrência de danos auditivos advindos da atividade militar naval na presença do agente físico ruído. $\mathrm{O}$ aparecimento da perda auditiva pôde ser observado tanto nos anos iniciais da profissão (em situações de curto tempo de exposição ao agente perturbador), durante treinamentos e cursos, quanto no aumento do tempo de serviço.

Posta a heterogeneidade de atividades militares encontradas nos estudos (operativos de terra, aviadores e embarcados) e diante das diversas formas de análise utilizadas, não foi possível elaborar um quadro característico de perfil da população estudada. Foi possível observar um padrão de estratificação das amostras por idade e sexo; e, em contrapartida, raça e tempo de serviço foram menos analisados como fatores de risco.

Pôde-se inferir que há um aumento da prevalência de perda auditiva em função do aumento da idade nos estudos que utilizavam essa variável. Para os outros, observou-se predominância numérica da raça branca e do sexo masculino, que pode refletir um viés, já que: 1) a inserção da mulher na carreira militar é menor e posterior ao homem; 2) ainda nos dias de hoje, algumas funções são desempenhadas apenas por militares do sexo masculino; 3) nos países onde foram realizados os estudos analisados predomina a raça branca.

As características auditivas mais prevalentes demonstraram perdas auditivas nas altas frequências, sendo citadas nos diferentes estudos como 
sensório-neurais permanentes ou induzidas por ruído. Alguns desses militares podem estar expostos a outros agentes nocivos à saúde auditiva, os quais podem potencializar os efeitos do ruído, amplificando a perda de audição e causando consequências na comunicação desses indivíduos.

Recomenda-se o cuidado e o acompanhamento dos militares da Marinha e de outras Forças Armadas e auxiliares por meio da promoção da saúde auditiva e prevenção da exposição ao ruído e a outros agentes ototóxicos. Isso pode ser feito mediante monitoramento dos níveis de exposição ao ruído, uso de proteção auditiva adequada à situação e, principalmente, conscientização quanto aos perigos desse agente e treinamento para a adoção de medidas preventivas.

A vulnerabilidade desse grupo reforça, portanto, a necessidade de inserção do Programa de Conservação Auditiva nas organizações militares a fim de monitorar e desenvolver ações pertinentes e eficazes no ambiente ocupacional.

\section{Contribuições de autoria}

Bernardo LD e Neves EB participaram do delineamento do estudo, do levantamento e análise dos dados e da elaboração e revisão crítica do manuscrito. Os autores aprovaram a versão final publicada e assumem responsabilidade integral pelo trabalho realizado e pelo conteúdo aqui publicado.

\section{Referências}

1. National Institute for Occupational Safety and Health (NIOSH). Noise and hearing loss prevention [Internet]. Atlanta: Centers for Disease Control and Prevention; 18 nov 2016 [citado em 19 out 2017]. Disponível em: https://www.cdc.gov/ niosh/topics/noise/

2. Nelson JT, Swan AA, Swiger B, Packer M, Pugh MJ. Hearing testing in the U.S. Department of Defense: potential impact on veterans affairs hearing loss disability awards. Hear Res. 2017;349:13-20.

3. Brasil. Ministério da Saúde. Secretaria de Atenção à Saúde. Departamento de Ações Programáticas Estratégicas. Perda auditiva induzida por ruído (Pair). Brasília, DF: Ministério da Saúde; 2006.

4. Yankaskas K. Prelude: noise-induced tinnitus and hearing loss in the military. Hear Res. 2013;295:3-8.

5. Irgens-Hansen K, Baste V, Bråtveit M, Lind O, Koefoed VF, Moen BE. Hearing loss in the Royal Norwegian Navy: A longitudinal study. Noise Health. 2016;18(82):157-65.

6. Turan O, Helvacioglu IH, Insel M, Khalid H, Kurt RE. Crew noise exposure on board ships and comparative study of applicable standards. Ships Offshore Struct. 2011; 6(4):323-38.

7. Kim SH, Lim EJ, Kim TH, Park JH. Long-term effect of noise exposure during military service in South Korea. Int J Audiol. 2017;56(2):130-6.

8. Almeida Filho N, Paim JS. Conceitos de saúde-doença: atualização do debate teóricometodológico. In Paim, JS, Almeida Filho, N. Saúde coletiva: teoria e prática. Rio de Janeiro: MedBook; 2014.

9. Yong JS, Wang DY. Impact of noise on hearing in the military. Mil Med Res. 2015;2:1-6.
10. Gordon JS, Griest SE, Thielman EJ, Carlson KF, Helt WJ, Lewis MS, et al. Audiologic characteristics in a sample of recently separated military Veterans: the Noise Outcomes in Servicemembers Epidemiology Study (NOISE Study). Hear Res. 2017;349:21-30.

11. Neves EB. Occupational risk management in the Brazilian army: normative and practical aspects. Cad Saude Publica. 2007; 23(9):2127-33.

12. St Onge P, McIlwain DS, Hill ME, Walilko TJ, Bardolf LB. Marine Corps Breacher Training Study: auditory and vestibular findings. US Army Med Dep J. 2011:97-107.

13. Antonioli CA, Momensohn-Santos TM, Benaglia TAS. High-frequency audiometry hearing on monitoring of individuals exposed to occupational noise: a systematic review. Int Arch Otorhinolaryngol. 2016;20(3):281-9.

14. Helfer TM, Canham-Chervak M, Canada S, Mitchener TA. Epidemiology of hearing impairment and noise-induced hearing injury among U.S. military personnel, 2003-2005. Am J Prev Med. 2010;38(1 Suppl):S71-7.

15. Lie A, Skogstad M, Johannessen HA, Tynes T, Mehlum IS, Nordby KC, et al. Occupational noise exposure and hearing: a systematic review. Int Arch Occup Environ Health. 2016;89(3):351-72.

16. Brasil. Ministério da Saúde. Saúde Ambiental e Gestão de Resíduos de Serviços de Saúde. Brasília, DF: Ministério da Saúde; 2002.

17. Silva M, Santana VS. Ocupação e mortalidade na Marinha do Brasil. Rev Saude Publ. 2004;38(5):709-15.

18. Trost RP, Shaw GB. Statistical analysis of hearing loss among navy personnel. Mil Med. 2007;172(4):426-30. 
19. Pearson C. The characteristics of pure tone audiograms in a sample of Royal Marines after Operation Herrick 9. J R Nav Med Serv. 2011;97(3):123-6.

20. Irgens-Hansen K, Sunde E, Bråtveit M, Baste V, Oftedal G, Koefoed V, et al. Hearing loss in the royal Norwegian navy: a cross-sectional study. Int Arch Occup Environ Health. 2015;88(5):641-9.

21. Higgins JPT, Green S, editors. Cochrane handbook for systematic reviews of interventions version 5.1 [Internet]. 2011 [citado em 27 jan 2021]. Disponível em: https://training.cochrane.org/ handbook/archive/v5.1/

22. Joseph AR, Horton JL, Clouser MC, MacGregor AJ, Louie M, Galarneau MR. Development of a comprehensive Blast-Related Auditory Injury Database (BRAID). J Rehabil Res Dev. 2016;53(3):295-306.

23. Orsello CA, Moore JE, Reese C. Sensorineural hearing loss incidence among US military aviators between 1997 and 2011. Aviat Space Environ Med. 2013;84(9):975-9.

24. Gubata ME, Packnett ER, Feng XS, Cowan DN, Niebuhr DW. Pre-enlistment hearing loss and hearing loss disability among US soldiers and marines. Noise Health. 2013;15(66):289-95.

25. Le TN, Straatman LV, Lea J, Westerberg B. Current insights in noise-induced hearing loss: a literature review of the underlying mechanism, pathophysiology, asymmetry, and management options. J Otolaryngol Head Neck Surg. 2017;46(1):41.

26. Tardin, EB, Lima, LLG. A mulher militar brasileira no século XXI: antigos paradigmas, novos desafios. Ágora. 2016;22:70-82.
27. Baraldi GS, Almeida LC, Borges ACC. Evolução da perda auditiva no decorrer do envelhecimento.

Rev Bras Otorrinolaringol. 2007;73(1),64-70.

28. Souza RM, Francisco AC, Coelho AMS, Braga AC. O novo desafio da gestão industrial: proporcionar empregabilidade aos portadores de deficiência auditiva leve nos setores industriais. Espacios. 2014;35(13):6.

29. Neves EB, Soalheiro M. Hearing protection used by the military of the Brazilian Army: is it effective? Cien Saude Colet. 2010;15(3):889-98.

30. Brasil. Ministério do Trabalho. Portaria $\mathrm{n}^{0} 3.214$, de 8 de junho de 1978. Aprova as Normas Regulamentadoras - NR - do Capítulo V, Título II, da Consolidação das Leis do Trabalho, relativas a Segurança e Medicina do Trabalho. Diário Oficial da União [Internet]. 6 jul 1978 [citado em 28 jan 2021];1:10.423. Disponível em: https://www. diariodasleis.com.br/busca/exibelink.php?numli $\mathrm{nk}=1-94-13-1978-06-08-3214$

31. Muhr P, Johnson AC, Skoog B, Rosenhall U. A demonstrated positive effect of a hearing conservation program in the Swedish armed forces. Int J Audiol. 2016;55(3):168-72.

32. Talcott KA, Casali JG, Keady JP, Killion MC. Azimuthal auditory localization of gunshots in a realistic field environment: effects of open-ear versus hearing protection-enhancement devices (HPEDs), military vehicle noise, and hearing impairment. Int J Audiol, 2012;51(1):S20-S30.

33. Meinke DK, Murphy WJ, Finan DS, Lankford JE, Flamme GA, Stewart M, et al. Auditory risk estimates for youth target shooting. Int J Audiol. 2015;53(2):S16-S25. 